\title{
Lateral Medullary Syndrome
}

National Cancer Institute

\section{Source}

National Cancer Institute. Lateral Medullary Syndrome. NCI Thesaurus. Code C84807.

A syndrome caused by an infarct in the vertebral or posterior inferior cerebellar artery. It

is characterized by sensory defects affecting the same side of the face as the infarct and the opposite side of the trunk as the infarct. Patients experience difficulty swallowing and/or speaking. 